www.jmscr.igmpublication.org

Index Copernicus Value: 79.54

ISSN (e)-2347-176x ISSN (p) 2455-0450

crossref DOI: https://dx.doi.org/10.18535/jmscr/v7i6.191

\title{
Etiology of rotator cuff tears: A Cross Sectional Study
}

Authors

Yawar Haider*, Obaid Nisar

Corresponding Author

Yawar Haider

Government Medical College, Srinagar, India

\begin{abstract}
Introduction: Rotator cuff tears are among the most common conditions affecting the shoulder. They have long been recognized as a cause of pain and disability. Most of the times the symptoms are insidious (other than traumatic causes) and first present as a loss of power when the arm is abducted and laterally rotated in simple everyday actions such as doing hair. The aim of this study was to determine the etiology of rotator cuff tears so that a viable treatment option could be offered to the patient population.

Materials and Methods: The present study was conducted in the Postgraduate Department of Orthopaedics, Hospital for Bone and Joint Surgery, Barzulla, Srinagar, an associate hospital of Government Medical College Srinagar Kashmir, from June 2015 to May 2018. This was a prospective study in which 175 unselected patients of either gender in the age group of 18 to 75 years with rotator cuff tear were asked about any history of trauma, duration of symptoms, and mode of trauma if present .

Results: Traumatic etiology was seen in 52\% of the cases. Indirect trauma to shoulder in the form of fall on an outstretched hand and lifting of heavy object accounted for $46.16 \%$ of cases and direct trauma to shoulder in the form of direct landing onto the shoulder or fall of a weight onto the shoulder accounted for $53.84 \%$ of cases.

Conclusion: Definitive traumatic incident as a precursor of symptoms was recognised in 91cases (52\%) while 84 cases (48\%) had no history of trauma.The younger population are more likely to have a history of trauma while as in older population the tears are mostly degenerative. In patients with degenerative tears, the bone quality is usually weaker and in such cases the suture anchors are directly placed into the bone without prior drilling in order to get a stronger hold and prevent suture anchor back-out.
\end{abstract}

\section{Introduction}

Rotator cuff tears are among the most common conditions affecting the shoulder. ${ }^{(1)}$ They have long been recognized as a cause of pain and disability. Most of the times the symptoms are insidious(other than traumatic causes) and first present as a loss of power when the arm is abducted and laterally rotated in simple everyday actions such as doing hair. ${ }^{(2)}$

The prevalence of shoulder problems based on consultations in primary care is estimated to be
$2.4 \%$. Between $30 \%$ and $70 \%$ of such shoulder pain is due to disorders of rotator cuff. ${ }^{(3)}$ Cadaveric studies have shown a $17 \%$ to $30 \%$ incidence of full thickness rotator cuff tears. Studies on asymptomatic patients have shown rotator cuff tear incidence of $20 \%$ to $54 \%$ in patients older than 60 years and $51 \%$ to $80 \%$ in patients older than $80 \mathrm{yrs}^{(4)}$. Also $4 \%$ of asymptomatic patients aged $<40 \mathrm{yrs}$ and $54 \%$ of patients aged $>60 \mathrm{yrs}$ having partial or complete tears of the rotator cuff on an MRI scan. ${ }^{(5)}$ 


\section{Etiology}

Rotator cuff tears can be acute or degenerative.

1. Traumatic Tears: Mostly caused by fall on outstretched arm or jerky movement during lifting of heavy weight. May be associated with other shoulder injuries like shoulder dislocation or clavicular fractures.

2.Degenerative Tears:- Most tears are of this type. Degeneration naturally occurs as we age. Several factors contribute:

a. Repetitive stress: sports activities like baseball, weight lifting, rowing etc. involving overuse of the cuff muscles.

b. Lack of blood supply: as age progresses with inability to repair tendon damage ultimately leading to tear.

c. Impingement: from bony spurs that develop with age on the undersurface of the acromion.

\section{Materials and Methods}

The present study was conducted in the Postgraduate Department of Orthopaedics, Hospital for Bone and Joint Surgery, Barzulla, Srinagar, an associate hospital of Government Medical College Srinagar Kashmir, from June 2015 to May 2018. This was a prospective study in which 175 unselected patients of either gender in the age group of 18 to 75 years with rotator cuff tear were asked about any history of trauma, duration of symptoms, and mode of trauma if present. Every patient attending to emergency or out-patient department was asked about mode of trauma, presence of any other comorbidity, whether participating in any sports activity. A record book was maintained to enter all the details of the patients with emphasis on etiology of the tear.

\section{Observations and Results}

Age Distribution

\begin{tabular}{|c|c|c|c|}
\hline S.No & Age(in years) & No. Of Cases & Percentage \\
\hline 1. & $18-30$ & 7 & 4 \\
\hline 2. & $31-40$ & 21 & 12 \\
\hline 3. & $41-50$ & 24 & 32 \\
\hline 4. & $51-60$ & 70 & 40 \\
\hline 5. & $61-70$ & 21 & 12 \\
\hline & Total & 175 & 100 \\
\hline
\end{tabular}

\section{Gender Distribution}

\begin{tabular}{|l|c|c|c|}
\hline S.No & Sex & No. Of Cases & Percentage \\
\hline 1. & Males & 63 & 36 \\
\hline 2. & Females & 112 & 64 \\
\hline & Total & 175 & 100 \\
\hline
\end{tabular}

\section{Side Involved}

\begin{tabular}{|l|c|c|c|}
\hline S.No & Side Involved & No. Of Cases & Percentage \\
\hline 1. & Right & 147 & 84 \\
\hline 2. & Left & 28 & 16 \\
\hline & Total & 175 & 100 \\
\hline
\end{tabular}

\section{History of Trauma}

\begin{tabular}{|l|c|c|c|}
\hline S.No & Mode & No. Of Cases & Percentage \\
\hline 1. & Traumatic & 91 & 52 \\
\hline 2. & Non-Traumatic & 84 & 48 \\
\hline & Total & 175 & 100 \\
\hline
\end{tabular}

\section{Mode of Injury}

\begin{tabular}{|l|c|c|c|}
\hline S.No & Mode of injury & No. Of cases & Percentage \\
\hline 1. & $\begin{array}{c}\text { Fall on outstretched } \\
\text { hand }\end{array}$ & 35 & 38.46 \\
\hline 2. & Direct fall on shoulder & 45 & 49.45 \\
\hline 3. & Lifting of heavy object & 7 & 7.69 \\
\hline 4. & $\begin{array}{c}\text { Fall of weight onto } \\
\text { shoulder }\end{array}$ & 4 & 4.39 \\
\hline & Total & 91 & 100 \\
\hline
\end{tabular}

Male:Female ratio in our study was 1:1.7

Right side was more commonly involved in our study.

Traumatic etiology was seen in $52 \%$ of the cases. Indirect trauma to shoulder in the form of fall on an outstretched hand and lifting of heavy object accounted for $46.16 \%$ of cases and direct trauma to shoulder in the form of direct landing onto the shoulder or fall of a weight onto the shoulder accounted for $53.84 \%$ of cases.

The mean age in our series was 51.48 years with range from 18-75 years. In patients with traumatic history, mean age was 47.61 years with range from 18 to 60 years. In patients with no history of trauma, mean age was 55.66 years with range from 40 to 75 years.

\section{Discussion}

The present study was conducted in Post-graduate department of Orthopaedics, Bone and Joint Surgery Hospital, an associate hospital of Government Medical College, Srinagar from June 2015 to May 2018 
The aim of this study was to determine the etiology of rotator cuff tears, whether traumatic or degenerative and also the mode of injury when present.

In our study, right shoulder which was the dominant arm in all cases was involved in 147 cases $(84 \%)$ and left side in only 28 cases $(16 \%)$.

Sugaya et al $2005,{ }^{(6)}$ compared the functional and structural outcome after arthroscopic full thickness rotator cuff repair in 80 patients. Dominant arm was involved in $77.5 \%$ of cases.

In our study, definitive traumatic incident as a precursor of symptoms was recognised in 91 cases (52\%).

Michael E. Hantes et al., ${ }^{(7)} 2011$ evaluated 223 patients with rotator cuff tear and found traumatic etiology in 39 cases(17.48\%).

Sorensen AK et al., ${ }^{(8)} 2007$ reported 50\% cases in his study after trauma to shoulder after detailed history and proper clinical evaluation.

Most common mode of injury in our series was direct fall onto the shoulder accounting for 45 out of 91 traumatic cuff tears $(49.45 \%)$. Indirect mechanism including fall on an outstretched hand and lifting of a heavy object accounted for 42 out of 91 traumatic cases $(46.15 \%)$.

Sorensen AK et al., ${ }^{(8)} 2007$ reported that in his study, $51 \%$ were injured by a direct trauma to the shoulder, $44 \%$ by an indirect trauma and $5 \%$ by a combined or unknown mechanism.

\section{Conclusion}

- The mean age in our series was 51.48 years with range from 18 to 75 years.

- Majority of the patients were females. Male to female ratio was 1:1.7 with $36 \%$ males and $64 \%$ females

- Right side (dominant arm in all) was involved in $84 \%$ patients and $16 \%$ patients had left side involvement.

- Definitive traumatic incident as a precursor of symptoms was recognised in 91 cases $(52 \%)$ while 84 cases $(48 \%)$ had no history of trauma.
This implies that younger population are more likely to have a history of trauma while as in older population the tears are mostly degenerative. In patients with degenerative tears, the bone is usually weaker and in such cases the suture anchors are directly placed into the bone without prior drilling in order to get a stronger hold and prevent suture anchor back-out.

\section{References}

1. De Palma AF, Callery G, Bennett GA. Variational anatomy and degenerative lesions of the shoulder joint. Instr Course Lect. 1949;6:255-81

2. Debeyre J, Patte D, Elmelik E. Repair of ruptures of the rotator cuff of the shoulder. J Bone and Joint Surg.1965; vol.47-B, no.1:36-42.

3. Rees JL. The pathogenesis and surgical treatment of tears of the rotator cuff. Journal of bone and joint surgery. 2008; vol.90B, no.7;827-32.

4. Lindley K, Jones GL. Outcomes of arthroscopic versus open rotator cuff repair, a systematic review of the literature. The American Journal of Orthopaedics. 2010;vol.39,no.12:592-600.

5. Zlatkin MB, Sher JS, Uribe JW, Posada A, Murphy BJ. Abnormal findings on magnetic resonance images of symptomatic shoulders. J Bone Joint Surg Am 1995;vol 77-A:10-15.

6. Sugaya H, Maeda K, Matsuki K, Moriishi J. Functional and structural outcome after arthroscopic full thickness rotator cuff repair: Single row vs dual row fixation. Arthroscopy 2005;21:1307-1316.

7. Hantes ME, Karidakis GK, Vlychou M, Varitimidis S, Dailiana Z, Malizos KN. A Comparison of early versus delayed repair of traumatic rotator cuff tears Knee Surg Sports Traumatol Arthrosc.2011:DOI 10.1007/s00167-011-1396-1

8. Sorensen AK, Bak K, Krarup AL, Thune $\mathrm{CH}$, Nygaard M, Jorgensen $\mathrm{U}$ et al. Acute 
rotator cuff tear: Do we miss the early diagnosis? A prospective study showing a high incidence of rotator cuff tears after shoulder trauma. J Shoulder Elbow Surg.2007;vol.16,no.2:174-80. 